\title{
"Je suis Charlie" de um ponto de vista marroquino: questões de alteridade após os atentados de Paris de 2015
}

Bruno Ferraz Bartel

Universidade Federal Fluminense, Niterói, Rio de Janeiro, Brasil

DOI 10.11606/issn.2316-9133.v25i25p131-150

resumo $\mathrm{O}$ artigo visa interpretar a produção de alteridades a partir da questão da liberdade de imprensa aos meios de comunicação do Marrocos criada pelos ataques à sede do jornal Charlie Hebdo em janeiro de 2015, Paris. A mobilização de argumentos religiosos na mídia marroquina fez com que o repúdio aos eventos ocorridos tivesse uma controvérsia entre projetos que envolvam diálogos a partir da produção de alteridades. De um lado, a sacralidade da liberdade de imprensa, que se impõe como um importante valor moral no processo de secularização francês. De outro, a sacralização da figura do profeta Mohammed cria as condições para se discutir as formas de poder que estabelecem os limites da liberdade de imprensa.

palavras-chave Alteridade; Moralidades; Islã; Marrocos; Liberdade de imprensa.

“Je suis Charlie" through a Moroccan point of view: question of alterity after 2015 attacks in Paris

abstract This article analyses the production of alterities from the freedom of the press in Moroccan media imposed by the terrorist attacks in Paris on January, 2015. The mobilizations of religious arguments in the Moroccan media gave the repudiation of the occurred events a controversy between projects involving the dialogues about the production of the alterity. On the one hand, the sacredness of the freedom of the press stands out as an important moral value in the process of French secularism. On the other, the sacralization of Prophet Mohammed's figure creates the conditions to discuss the forms of power that set the limits of the freedom of Moroccan press.

keywords Alterity; Moralities; Morocco; Islam; Freedom of the press. 
O artigo visa interpretar a produção de alteridades a partir da questão da liberdade de imprensa dos meios de comunicação do Marrocos proporcionada pelos ataques à sede do jornal Charlie Hebdo em Paris, em janeiro de 2015. Os Irmãos Kouachi (Said e Chérif) foram identificados pela polícia francesa como os principais suspeitos de serem os homens armados e mascarados que provocaram o ataque, motivados por suas ligações tanto com a Al-Qaeda quanto com o Estado Islâmico do Iraque e do Levante (Isis). A mobilização de argumentos religiosos na mídia marroquina fez com que o repúdio aos eventos ocorridos tivesse um limite de apoio político ao discurso oficial francês. Sendo assim, a contextualização das moralidades em disputa, durante a cobertura desses acontecimentos, se torna fundamental para a explicitação dos valores sociais em jogo e atuantes no país.

Criado em novembro de 1970, o jornal satírico francês Charlie Hebdo publica semanalmente crônicas sobre política, economia e demais temas da sociedade francesa, mas também, ocasionalmente, publicações envolvendo questões estrangeiras. As controvérsias entre os fundamentalistas islâmicos e o jornal francês começaram em 2006, quando este reproduziu charges do jornal dinamarquês Jyllands-Posten sobre o profeta Mohammed, publicadas inicialmente em 2005. Essas caricaturas provocaram uma série de atos violentos por parte de extremistas islâmicos europeus contra as embaixadas Dinamarquesas. Por motivos de segurança, a polícia francesa era mobilizada esporadicamente para proteger a sede do Charlie Hebdo.

Após os atentados de 7 de janeiro de 2015, que vitimaram os cartunistas do periódico parisiense, a temática da liberdade de imprensa retornou ao espaço público marroquino por conta das publicações das charges contendo a figura do profeta Mohammed. A primeira edição desse jornal semanal satírico francês, uma semana depois dos eventos ocorridos em Paris, trouxe consigo a célebre frase "Je suis Charlie" [eu sou Charlie] em apoio às vítimas do massacre. Tal síntese acabou não apenas funcionando como um símbolo de defesa da liberdade de imprensa na França, mas também reforçou o debate sobre as múltiplas formas da presença do islã no país.

As críticas da Liga Árabe e da União Africana aos atentados em solo francês representaram um ganho de aliados na luta contra o radicalismo islâmico na Europa e no mundo. Entretanto, algumas divergências políticas relativas aos pormenores do que se define como os limites dessa liberdade de imprensa do "Ocidente" novamente foram levantados por países do Oriente Médio (Egito, Jordânia, Arábia Saudita), Norte da África (Tunísia, Argélia, Marrocos) e pelas demais nações onde a religião islâmica é majoritária (Indonésia, Sudão, Nigéria).

No Marrocos, a circulação do número 1178 do Charlie Hebdo, que trazia a imagem do profeta Mohammed com um cartaz no qual se lia "Je suis Charlie" (Eu sou Charlie), com o título extra de "Tout est Pardonné" [está tudo perdoado], em resposta ao ocorrido com os cartunistas, foi proibida pela monarquia Alauita ${ }^{1}$ do rei 
Mohammed VI, no poder desde 1999. O rei inclusive se recusou a participar da marcha organizada em Paris, que contou com líderes de diversas nações, em solidariedade a François Hollande (atual presidente francês). Além disso, o periódico marroquino MarocHebdo estampou em sua capa, dois dias após a edição do jornal da Charlie Hebdo, uma imagem contendo milhares de mulçumanos em peregrinação à cidade de Meca (cidade sagrada para a religião islâmica) com a frase: "Je suis mahométan" [eu sou muçulmano].

Embora o conteúdo da revista criticasse o uso da violência contra os cartunistas, reforçando a imagem de um Marrocos combatente dos grupos ligados a um fundamentalismo islâmico, a exposição da figura do profeta Mohammed em um jornal satírico não deixou de ser apontada como uma possibilidade real de incitação ao ódio por parte de alguns marroquinos. Logo, o que se veria ao longo de todo o mês de janeiro de 2015 seria uma série de debates nos meios de comunicação do país (televisão, rádio, internet e mídia impressa) sobre os limites e as razões pelas quais se insistia em representar o profeta Mohammed. As argumentações religiosas presentes na mídia marroquina reafirmaram a proibição de se fazer uso da representação de Mohammed, devido ao seu caráter sacro, e exigiram também um compromisso por parte da comunidade marroquina que vive na França de repudiar quaisquer outros atos do mesmo tipo repetidos na Europa. Além disso, a tensão entre o que se define como liberdade de imprensa, inspirada em processos de secularização, ou seja, como categoria epistêmica e doutrina política (ASAD, 2003), e a capacidade de agência da religião em sociedades islâmicas, como no caso do Marrocos, fornece um contexto específico de imbricação e tensão entre política e religião.

A construção dessas questões surgiu quando eu realizava minha segunda pesquisa etnográfica no Marrocos, como parte de um exercício exploratório para o desenvolvimento de minha tese de doutorado. $\mathrm{O}$ método que fundamenta a maioria dos meus argumentos se baseia em observações dos principais meios de comunicação do país (debates televisivos e mídias impressas de ampla circulação) como forma de compor um quadro relativo aos conteúdos transmitidos e veiculados, responsáveis pela criação de uma visão maioritária local durante todo o mês de janeiro de 2015. Além disso, confrontei algumas dessas informações por meio de conversas informais com alguns interlocutores (8 homens e 4 mulheres na faixa etária entre 20 e 55 anos, residentes nas cidades de Rabat e Meknes e na vila de Sidi 'Ali), procurando, assim, indicar variações presentes em diversos setores da sociedade marroquina (instituições religiosas, setores privados e públicos).

Seja como for, o que os atentados de Paris parecem indicar é a controvérsia entre projetos que envolvam diálogos a partir da produção de alteridades. De um lado, a

\footnotetext{
${ }^{1}$ A dinastia Alauita assumiu o poder sobre os territórios que viriam a ser o Marrocos em 1664 e se encontra, até o presente, como o poder governante do Reino do Marrocos.
} 
sacralidade da liberdade de imprensa, que se impõe como um importante valor moral no processo de secularização francês. De outro, a sacralização da figura do profeta Mohammed cria as condições para se discutir as formas de poder que estabelecem os limites da liberdade de imprensa marroquina. No final das contas, a incomunicabilidade desses diversos domínios se configura como um obstáculo tanto na percepção quanto no trato das diferenças existentes entre o que se considera "sagrado".

A exposição da imagem do profeta Mohammed suscita uma problemática no espaço europeu, o que também não deixa de gerar polêmicas entre os países, como Marrocos, com populações de maioria muçulmana. O presente artigo se divide em três partes. Na primeira, descrevo um balanço do evento crítico ocorrido em solo francês, que mobilizou a "fúria" de muçulmanos pelo suposto uso indevido da figura sacra do profeta, e procuro apontar alguns efeitos iniciais no Marrocos. Já na segunda parte, analiso algumas posições da mídia marroquina sobre o caso, como nas controvérsias produzidas pela revista MarocHebdo, além de incluir alguns posicionamentos elaborados a partir dessas discussões entre certos interlocutores da pesquisa. Por fim, na última parte, apresento minhas conclusões sobre os processos de objetificação a partir da imagem do profeta Mohammed e sua relação com a produção de alteridades.

\section{A produção do "outro"}

A produção da alteridade é um dos aspectos marcantes e atuantes em todas as sociedades humanas. A classificação dos limites entre coisas, classes ou grupos (um "nós" em oposição a "eles") já foi desenvolvida em termos de 1) es-

\footnotetext{
${ }^{2}$ Émile Durkheim (2008) já havia explicitado que as dimensões entre o sagrado e o profano foram concebidas pelo espírito humano como gêneros separados através de uma idealização do mundo, ou seja, a partir da capacidade dos homens de conceberem um ideal e de acrescentá-lo ao real. $\mathrm{O}$ aspecto característico do fenômeno religioso é o fato de que ele pressupõe uma divisão do universo conhecido e conhecível em dois gêneros que compreendem tudo o que existe, mas que se excluem radicalmente. As coisas sagradas são aquelas que os interditos protegem e isolam; as coisas profanas, por sua vez, aquelas às quais esses interditos se aplicam e que devem permanecer à distância das primeiras.

3 "classificar coisas é ordená-las em grupos entre si, separados por linhas de demarcação nitidamente determinadas" (DURKHEIM; MAUSS, 2005, p. 400), ou seja, "classificar não é apenas constituir grupos: é dispor estes grupos segundo relações muito especiais” (DURKHEIM; MAUSS, 2005, p. 403).

4 "o desejo de se opor, de se distinguir, de ser o que se é. Muitos costumes surgiram menos por alguma necessidade interna ou acaso favorável do que da simples vontade de não ficar por baixo, em relação a um grupo vizinho que submetesse a normas precisas algum capo de pensamento ou de atividade no qual não se tivesse pensado em impor regras" (LÉVI-STRAUSS, 2013, p. 362).
} 
pontaneidade associada a uma necessidade lógica ${ }^{3}$ (Durkheim; Mauss, 2005); 2) pulsão humana por se distinguir ${ }^{4}$ (Lévi-Strauss, 2013); 3) ou, até mesmo, a de invenção humana ${ }^{5}$ (Wagner, 2010). A significação moral contida nos elementos valorizados pelos grupos sociais atesta a capacidade inerente a cada um deles de dispor de suas experiências segundo uma "ordem hierárquica da qual nem o mundo sensível nem nossa consciência nos oferecem o modelo" (Durkheim; Mauss, 2005, p. 403). Nesse sentido, a produção de valores concorrentes estabelece as múltiplas fronteiras de inclusão e/ou exclusão de determinadas crenças, atitudes, motivações e, especialmente, de práticas que favorecem a constituição de grupos sociais.

Os acessos a essas linhas de pertencimento são constantemente negociados para a manutenção das fronteiras e dos fatores socialmente relevantes (Barth, 2000; 2005). Entretanto, contrariando uma abordagem que visa classificar as pessoas e os grupos locais como membros de um "grupo étnico", por exemplo, a partir de traços culturais particulares ou arroladas em séries de traços que as formas culturais aparentes exibem sobre a ecologia (Barth, 2000), procuro explorar a noção de "senso comum" de Clifford Geertz (2006) como um corpo organizado de pensamento deliberado, "capaz de lidar com os problemas cotidianos, de uma forma cotidiana, e com alguma eficácia” (Geertz, 2006, p. 115). Essa convicção que o homem comum aparentemente possui, de que tem o controle de tudo, lhe dá alguma possibilidade de agir sobre o mundo através do uso de seu "bom senso", 6 que seria uma forma de explicar os fatos da vida. ${ }^{7}$

Para tal proposta, é preciso lembrar que o que se denomina de "cultura" está sempre em fluxo e em mudança, mas também sempre sujeita a formas de controle (Barth, 2005). Se o senso comum pode ser encarado como um "sistema cultural", como nos descreve Geertz (2006), as suas propriedades podem

\footnotetext{
5 "Nossa Cultura é um estilo de vida que escolheu traçar suas distinções convencionais deliberada e conscientemente, em vez de precipitá-las. É isso que queremos dizer com 'regras', uma moralidade da articulação deliberada e artificial. E porque nós 'fazemos' convenção, temos de 'ser' e sofrer as exigências da invenção, sua antítese natural. A invenção é nossa surpresa, nosso mistério, nossa necessidade natural" (WAGNER, 2010, p. 128).

6 "Como estrutura para o pensamento, ou uma espécie de pensamento, o bom senso é tão autoritário quanto qualquer outro: nenhuma religião é mais dogmática, nenhuma ciência mais ambiciosa, nenhuma filosofia mais abrangente" (GEERTZ, 2006, p. 127). Além disso, "o bom senso tem a pretensão de ir além da ilusão para chegar à verdade, ou, como costumamos dizer, chegar às coisas como elas realmente são" (GEERTZ, 2006, p. 128).

7 "o esquema da classificação não é produto espontâneo do entendimento abstrato, mas resulta de uma elaboração na qual entraram todos os tipos de elementos estranhos" (DURKHEIM; MAUSS, 2005, p. 403).
} 
estar imbricadas ao campo de poder existente na construção das fronteiras pelos indivíduos, consciente ou inconscientemente, a partir de suas interações, criando uma ideia de "cultura". Os principais processos criativos e expansivos de conhecimento não são limitados na sua capacidade de produzir uma variação contínua. Dito de outra maneira, o senso comum possui processos de controle, silenciamento e, inclusive, apagamento, atuantes sobre algumas experiências.

A crença nas fronteiras que criam a experiência de lidar com grupos sociais "homogêneos" (um "nós" em oposição a "eles") é possível através de exemplos religiosos. Entre sociedades como as islâmicas, o conceito de "objetificação" figura como parte do processo pelo qual questões fundamentais podem vir à tona na consciência de um grande número de crentes, tais quais: "Qual é a minha religião?", "Por que ela é importante para a minha vida?” e "Como as minhas crenças guiam a minha conduta?” (Eickelman; Piscatori, 1996, p. 38). A objetificação não pressupõe a noção de que a religião é uma entidade uniforme ou monolítica (muito embora ela seja precisamente isso para alguns indivíduos). Essas perguntas "objetivas", amplamente compartilhadas, se constituem em consultas modernas que cada vez mais moldam o discurso e a prática de muçulmanos em todas as classes sociais, assim como algumas delas procuram legitimar as suas ações e crenças, afirmando que elas defendem um retorno a formas tradicionais supostamente "autênticas” (Eickelman; Piscatori, 1996). Neste sentido, o conceito de objetificação pode ser usado entre amplos grupos sociais, uma vez que a religião islâmica se tornou um sistema autosuficiente em que seus adeptos podem descrever, caracterizar e, fundamentalmente, se distinguir diante de outros sistemas de crença.

Da invenção do "outro" (islã) aos atentados ao jornal Charlie Hebdo

A imigração muçulmana para a Europa foi um fenômeno bastante discreto até a Segunda Guerra Mundial. O governo francês tentou mesmo capitalizar a pequena presença muçulmana para a sua política colonial, declarando a França uma "potência muçulmana" através da inauguração da Mesquita de Paris, em 1926 (Pinto, 2010). A situação mudou dramaticamente nos anos 1950, quando a demanda de mão de obra para a reconstrução da Europa fez com que os governos europeus abrissem suas portas e incentivassem a imigração de suas colônias, ex-colônias ou países do Mediterrâneo.

As comunidades muçulmanas criadas pelos imigrantes foram acrescidas pelas novas gerações nascidas nos países que os acolheram e pelo processo de conversão de não muçulmanos locais (MAPRIL, 2012). Embora a conversão ao islã na Europa costume receber muita atenção da mídia, ela geralmente ocorre em

\footnotetext{
${ }^{8}$ A objetificação garantiria a transformação de um código cultural em uma prática adotada pelos indivíduos consciente ou inconscientemente (EICKELMAN; PISCATORI, 1996).
} 
bases individuais e é contrabalançada pelos muçulmanos que abandonam o islã por outras religiões ou pelo agnosticismo (Pinto, 2010). Através da imigração e das conversões, o islã adquiriu uma significativa presença religiosa no velho continente (5,8\% na Alemanha; 7,5\% na França; 4,8\% no Reino Unido; e 3,7\% na Itália, segundo dados do Pew Research Center para o ano de 2010).

Mais que um simples fato demográfico, as comunidades muçulmanas na Europa foram investidas de significados políticos e simbólicos no corrente debate sobre a suposta incompatibilidade de valores entre construções ideológicas denominadas como "islã" e "Ocidente" (entendidos aqui como invenções para descrever e situar blocos homogêneos). Esse debate ganhou força após o 11 de setembro (2001), em Nova York, e os ataques terroristas em Madrid (2004) e Londres (2005), quando os sinais de alienação cultural e de militância radical entre as comunidades muçulmanas da Europa passaram a ser vistos como um terreno fértil para o surgimento do "terrorismo islâmico". A ideia de que os muçulmanos constituem uma espécie de "quinta coluna" que ameaça o caráter liberal e democrático das sociedades ocidentais é bastante difundida na opinião pública europeia, sendo constantemente mobilizada por partidos e grupos políticos em benefício de suas agendas particulares.

Nos seguintes termos foi descrito o evento crítico de Paris ocorrido em 7 de janeiro de 2015 pelo jornal Le Monde:

L'attaque a décimé la rédaction de Charlie Hebdo. Parmi les morts figurent de nombreux journalistes, dont les dessinateurs Charb, Cabu, Wolinski, Tignous, Honoré, Elsa Cayat, Mustapha Ourad ainsi que Bernard Maris, chroniqueur pour Charlie Hebdo et France Inter.

Un agent d'entretien de l'immeuble, Frédéric Boisseau, 42 ans, collaborateur de Sodexo, et un invité de la rédaction, Michel Renaud, ont également péri dans l'attaque. Selon le procureur, deux policiers clôturent ce macabre bilan. L'un, le brigadier Franck Brinsolaro, du Service de la protection (SDLP, ex-SPHP) était chargé de la sécurité de Charb, selon des sources syndicales policières. L'autre, Ahmed Merabet, a été tué à l'extérieur, alors que les assaillants prenaient la fuite.

Il s'agit de l'attentat le plus meurtrier en France depuis celui de l'Organisation armée secrète (OAS) contre un train Strasbourg-Paris, qui avait fait 28 morts en 1961, durant la guerre d'Algérie. 
Le procureur de Paris, François Molins, a également annoncé que onze personnes avaient été blessées, dont quatre grièvement, parmi lesquelles le journaliste Philippe Lançon et deux policiers. Selon les informations du Monde, Philippe Lançon, critique littéraire à Libération et chroniqueur régulier de Charlie, a été grièvement blessé au bas du visage par une balle. Il a été opéré à la Pitié-Salpêtrière, et ses jours ne sont pas en danger.

Le procureur Molins a livré dans la soirée un premier récit des événements. Au moins deux hommes cagoulés et vêtus de noir se sont introduits vers $11 \mathrm{~h} 30$ dans les locaux de Charlie Hebdo après s'être d'abord trompés d'adresse, croyant trouver la rédaction au numéro 6 de la rue Nicolas-Appert.

Armés de kalachnikovs, ils ont tiré sur une personne qui se trouvait à l'accueil, avant de monter à l'étage pour atteindre la rédaction de Charlie Hebdo. Les journalistes étaient alors en pleine conférence de rédaction hebdomadaire. Les assaillants ont commencé à tirer sur les dessinateurs et journalistes, comme l'a relaté Coco, dessinatrice au journal, qui a précisé que les hommes parlaient parfaitement le français et se revendiquaient d'Al-Qaida. ${ }^{9}$

Além de noticiar as mortes dos cartunistas, a matéria fez menção ao nome da Al-Qaeda (grupo liderado por Osama Bin Laden que orquestrou os ataques de 11/09 em Nova York) para evocar a imagem de um grupo homogêneo ligado à intolerância (como aconteceu nos atentados de Madrid e de Londres) aos valores da comunidade europeia, como, por exemplo, a da liberdade de imprensa de publicar charges envolvendo a figura do profeta. ${ }^{10}$ "Islã", "muçulmano" e "terrorista" seriam as palavras-chave para descrever as imagens produzidas pela opinião pública ao longo das semanas que se seguiram ao evento crítico de Paris, o que acabou reverberando com certas particularidades nos países de maioria islâmica, como o Marrocos.

9 "Charlie Hebdo visé par une attaque terroriste, deuil national décrété". Disponível em: <http://www.lemonde.fr/societe/article/2015/01/07/attaque-au-siege-de-charlie-hebdo_4550630_3224.html>. Acesso em: 2 jul. 2015.

${ }^{10}$ As polêmicas na Europa envolvendo as caricaturas do profeta Mohammed tiveram início em 30 de Setembro de 2005. Na época, o jornal dinamarquês Jyllands-Posten sofreu as primeiras retaliações tanto dos muçulmanos europeus quanto dos países de maioria islâmica. Um balanço desse evento foi publicado por Faavra Favret-Saada (2007). 


\section{A repercussão dos atentados no Marrocos: a questão do "outro" (Europa)}

O canal de televisão internacional France 24 noticiou que a capa do Charlie Hedbo pós-atentado ( $\mathrm{n}^{\circ}$ 1178) provocou distintas reações nos países com populações de maioria islâmica do Oriente Médio e do Norte da África. Para o canal televisivo marroquino $2 \mathrm{M}$, as autoridades religiosas ['alim; pl. 'ulama] no Marrocos foram categóricas em criticar a publicação com a figura do profeta Mohammed estampada acompanhada da frase "Tout est Pardonnee" [está tudo perdoado]. O rei Mohammed VI, denominado comandante da crença [amir al-mu'minin], ou seja, o "guardião" simbólico da religião islâmica do país, ordenou publicamente a proibição do jornal satírico em seu território como forma de contemplar os anseios da elite religiosa. ${ }^{11}$ Assim, o processo de objetificação (Eickelman; Piscatori, 1996) da imagem do profeta foi usado em favor da defesa dos valores religiosos marroquinos como forma de produzir uma distinção perante outros sistemas de crenças e de ação como, por exemplo, da laicidade francesa.

Mas nem tudo se resumiu a repúdio por parte dos marroquinos. No dia 9 de janeiro de 2015, centenas de pessoas se manifestaram no centro da capital (Rabat) em protesto aos atentados. Convocados através das redes sociais (Facebook e Twitter), muitos manifestantes compareceram ao ato, na frente do prédio de um veículo de comunicação francês, vestidos de preto e com uma vela em memória aos mortos. Alguns também carregavam cartazes com mensagens "Je suis Mohammed, mais je suis Charlie" [sou muçulmano, mas sou Charlie] ou "Je suis marrocain mais je suis aussi Charlie" [sou marroquino, mas também sou Charlie]. Entre os presentes, foi possível ver jornalistas, intelectuais laicos, militantes da esquerda e de organizações pró-direitos humanos e muitos professores universitários. O embaixador da França e outros diplomatas de sua delegação também compareceram ao protesto.

A disputa em torno da condenação ou da liberdade do uso da figura do profeta iria se prolongar durante todo o mês de janeiro de 2015 no país. A mídia proporcionou uma série de debates, enquetes e opiniões públicas como forma de apresentar e de posicionar os diversos grupos políticos, religiosos e demais setores da sociedade civil. A produção dessas distinções se pautou na defesa expressa dos reais interesses ligados de cada grupo, mais uma vez a partir dos valores mo-

\footnotetext{
${ }^{11} \mathrm{O}$ Marrocos proibiu a exibição do filme Exodus, uma grande produção de Hollywood, apenas um dia antes de sua estreia nas salas de cinema (25 de dezembro de 2014). O filme conta a história do profeta Moisés no Egito. Como sua figura é importante também para os muçulmanos, sua representação numa película cinematográfica foi algo condenável por parte das autoridades religiosas marroquinas.
} 
rais em jogo. As formas de controle, silenciamento e apagamento que um grupo impõe a outro foram notórias e expuseram os eixos de sacralidade do profeta provenientes da imagem de um senso comum atuante sobre a religião islâmica. Entre discursos afinados com perspectivas de valorização de um "islã universal", a partir do que se considera uma "tradição", e argumentos mais atípicos, centrados na crença em um "liberalismo universal", alguns meios de comunicação foram verdadeiros palcos de exibição de alteridades.

Apontar o que de "senso comum"/"objetificação" está contido nesstas disputas seria relevante, pois possibilita trazer à tona uma série de elementos geralmente descartados pelas análises sobre o que se denomina "cultura". Além disso, os meios pelos quais essas formas de "afirmação sobre um mundo" (a invenção de um "nós") são produzidas, distribuídas e organizadas sublinham as possibilidades de se entender a constituição dessas diferenças entre os grupos conflitantes. Nesse sentido específico, a televisão e a imprensa marroquina contribuem de maneira significativa para a produção (invenção) de um “outro".

\section{O papel das tecnologias: 0 canal $2 \mathrm{M} \mathrm{e}$ a revista MarocHebdo}

O primeiro ministro Abdelilah Benkirane (no poder desde 2011) recorreu ${ }^{12}$ à emissora mais vista $(2 \mathrm{M})$ no Marrocos para realizar uma entrevista na qual repudiou os ataques, mas também a forma com que alguns países da Europa difamam o Islã por meio de suas charges. ${ }^{13}$ Ele deixou claro a sua solidariedade às vítimas, mas também não poupou críticas ao que denominou de "teimosia do Ocidente" em menosprezar os valores dos muçulmanos espalhados no mundo. Ao longo de um programa de quase duas horas, o entrevistador intercalava a conversa com depoimentos de pessoas obtidos nas ruas do país sobre as charges, realizadas pela emissora durante os dias que sucederam as manifestações na França, e as repassavam para o seu convidado exigindo as suas ponderações a respeito das opiniões do público.

Os resultados dessas falas oscilavam sempre entre os dois polos: ser "contra" os usos da figura do profeta ou "a favor" deles. A decisão da $2 \mathrm{M}$ em ter o primeiro ministro (islamista moderado) nessa ocasião se constituiu em uma contraofensiva à manifestação ocorrida no dia 9 de janeiro na capital envolvendo os marroquinos "mais próximos" dos ideais franceses de "liberdade de expressão". O partido que Benkirane representa (PJD - Partido da Justiça e do Desenvolvimento), assentado nas alas tidas como "conservadoras" do país, exigia uma res-

\footnotetext{
${ }^{12}$ Benkirane já havia feito uma comunicação pública, no dia 8 de janeiro de 2015, sobre os ataques ao jornal Charlie Hebdo.

${ }^{13}$ Disponível em: http://www.medias24.com/Quoi-de-neuf/151958-Charlie-Hebdo-Benkirane-salue-la-position-du-Maroc.html. Acesso em 02 de julho de 2015. 
posta pública quanto ao apoio dos marroquinos a essas "tecnologias ocidentais" (no caso, as charges) perturbadoras de uma ordem moral islâmica.

A situação mais emblemática da imprensa marroquina seria a publicação da revista MarocHebdo (de 16 de janeiro) em oposição ao Charlie Hebdo (14 janeiro), uma vez que o periódico francês ganhou força a partir das manifestações ocorridas nas ruas da França em homenagem às vítimas e pela defesa de liberdade, valor herdado do Iluminismo do século XVIII. A matéria central intitulada "Je suis mahométan" [eu sou muçulmano] apresentava um grupo de pessoas segurando uma bandeira do Marrocos junto com outros indivíduos portando algumas bandeiras francesas nas mãos. Além disso, figuravam na imagem alguns cartazes com os dizeres: "L'islam est innocent du terrorisme" [o islã é inocente do terrorismo]. A publicação classificava os atentados como "atos odiosos", sem qualquer vinculação com o que se denomina "islã político", e se questionava sobre a quem interessaria provocar tais "crimes". No final, seus redatores exploraram a dimensão dos possíveis impactos aos muçulmanos (franceses e marroquinos) nas formas de se lidar com as diferenças religiosas presentes nos países europeus e em território marroquino. Entretanto, a matéria seguinte trouxe uma entrevista com um dos líderes da salafiy ${ }^{14}$ mais atuantes da atualidade marroquina: Mohammed Fizazi. ${ }^{15}$ Com o título "Charlie Hebdo sème la haine" [Charlie Hebdo semeia o ódio], ele classificou o periódico francês de explorador do humor e da liberdade de expressão justamente com o intuito de atiçar o ódio na religião muçulmana e entre as pessoas que a ignoram. Mohammed Fizazi apoiou a decisão do ministro dos Assuntos Estrangeiros (Salehedine Mezouar) de anular a sua participação na marcha de Paris junto com as demais autoridades europeias e mundiais. $\mathrm{O}$ fato de condenar a morte dos cartunistas não o impediu de propagar as suas ideias de que as caricaturas do profeta são uma "constante provocação injustificada sobre o sentimento de mais de 1 bilhão e meio de muçulmanos em todo o mundo". Além disso, ele foi categórico ao afirmar que o Charlie Hebdo

\footnotetext{
${ }^{14}$ Salafiyya ou salafismo é um termo usado para designar diferentes correntes reformistas que procuram restaurar o islã dos "precursores/ancestrais" (salaf), ou seja, do profeta e seus companheiros. O projeto do salafismo estava centrado na ideia que a volta às "origens" era uma forma de regenerar o islã, expurgando as inovações e adições que haviam desvirtuado a mensagem profética e causado o seu declínio civilizacional. Embora as diferentes correntes do salafismo dialogassem entre si, elas nunca constituíram um movimento unificado, pois o significado das "origens" e como elas deveriam ser recuperadas variavam de acordo com o contexto cultural no qual cada uma delas havia sido elaborada (PINTO, 2010).

${ }^{15}$ Mohamed Fizazi nasceu em 1950 em uma vila perto de Taza (a leste de Fez no Marrocos). É considerado um dos líderes religiosos "fundamentalistas" do país. Ele foi condenado a 30 anos de prisão, após os atentados de 16 de maio de 2003 em Casablanca, por sua influência ideológica sobre os responsáveis por esses ataques. Foi libertado da prisão em 14 de abril de 2011, depois do perdão real de Mohammed VI, o que lhe possibilitou a criação de seu partido político ainda sem representação parlementar: o Partido da Ciência e do Trabalho [hizb l'ilm wa l'amal].
} 
"pisoteou" na sacralidade de seu profeta e que a sua intenção de utilizar o recurso da "liberdade de expressão" somente permitiu todas essas repercussões como consequência.

A difusão desses conteúdos midiáticos entre a população marroquina ocorreu de maneira desigual, porém, existiria uma possibilidade de se verificar seu alcance e a sua influência entre os diversos setores da sociedade. A noção de um senso comum compartilhado poderia, então, ser visto de maneira "objetificada" entre alguns entrevistados, envolvendo a produção de alteridades (um "nós" em oposição a "eles"), a partir das considerações deliberadas sobre os usos da figura do profeta e sobre a situação atual que vive a religião islâmica na Europa. As perspectivas dessas pessoas podem lançar algumas luzes sobre os mecanismos de alteridade (controle, silenciamento e apagamento) mesmo que haja o recurso, por parte deles, da "invenção" de grupos homogêneos atuantes na realidade.

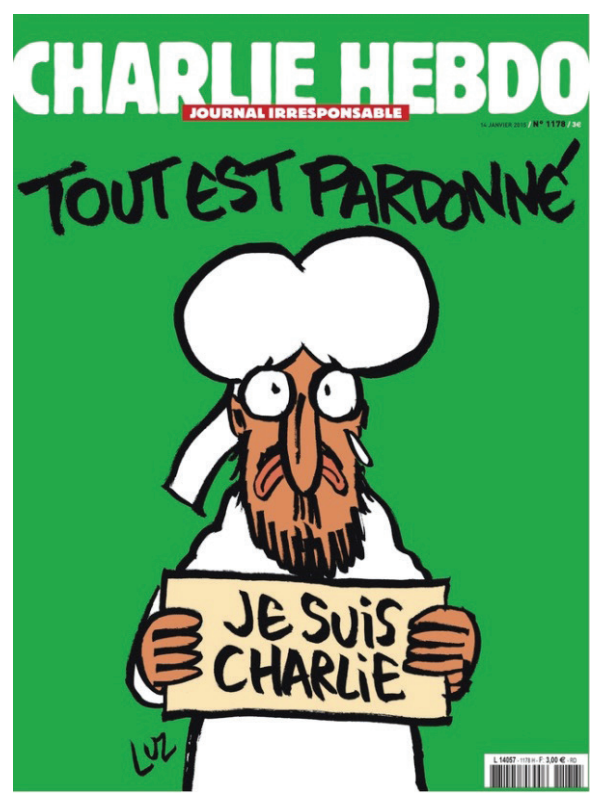

Figura 1 Capa da Edição no 1178 do Charlie Hedbo. 14 jan. 2015. Fonte: Liberation.

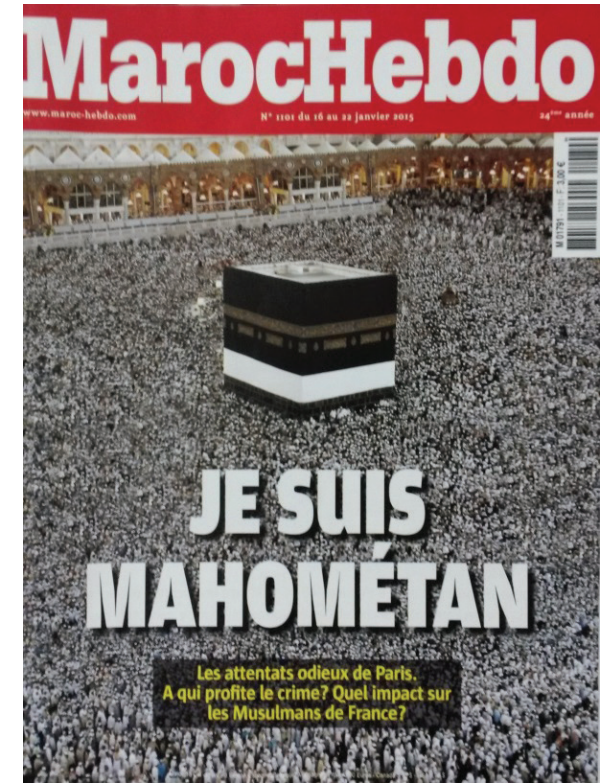

Figura 2 Capa da Edição no 1101 da MarocHebdo. 16-22 jan. 2015. Fonte: MarocHebdo. 


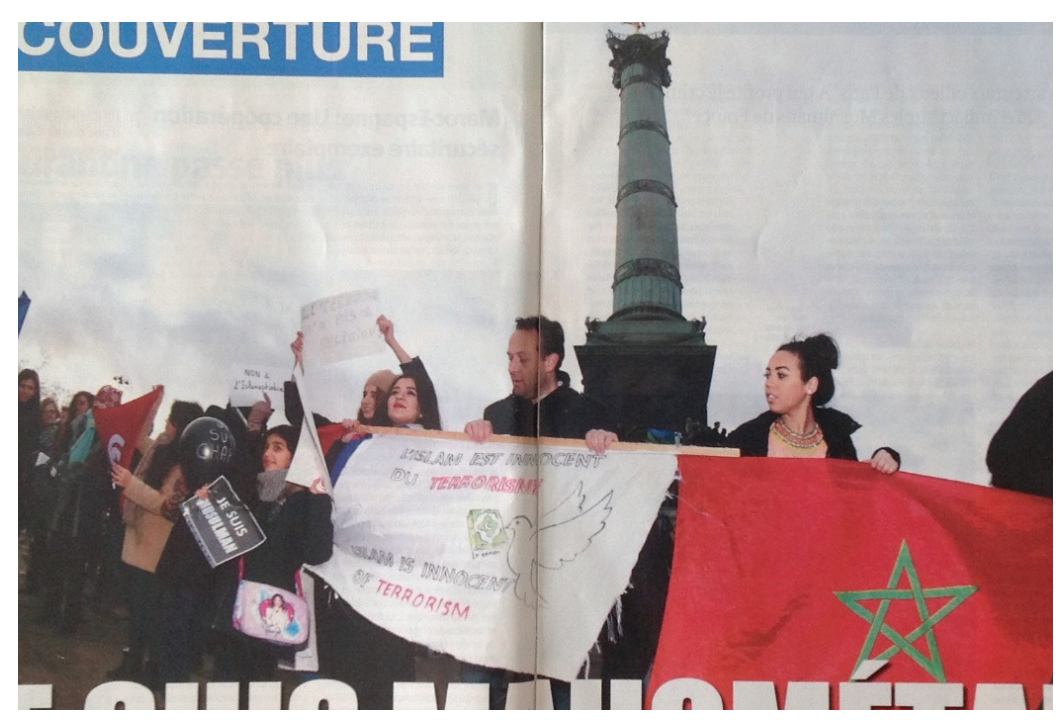

Figura 3 Matéria central da edição no 1178 da MarocHedbo. 14 jan. 2015. Fonte: MarocHebdo.

Considero que o momento atual experienciado por alguns dos interlocutores envolvidos no meu trabalho de campo, durante o mês de janeiro de 2015, em Rabat e na vila de Sidi 'Ali, pode ser útil na elaboração de um quadro que visa levantar algumas variáveis em disputa. Procuro fundamentar alguns dos objetivos do artigo não a partir de descrições "densas" (Geertz, 1989), histórias, trajetórias ou até mesmo biografias ${ }^{16}$ dos interlocutores. Penso dar muito mais ênfase ao que é do corpo organizado de pensamento deliberado, denominado de senso comum (Geertz, 2006), porém, também ao que é objetificado em discursos e práticas dos mulçumanos de todas as classes sociais (Eickelman; Piscatori, 1996). Mesmo que esse exercício contenha um caráter exploratório, isso não altera a sua importância em indicar as formas distintivas de valores utilizados pelos atores sociais escolhidos aqui e nem, tampouco, em circunscrever os arranjos morais existentes. Sendo assim, utilizo a seguir a trajetória de dois interlocutores como forma de expressar os valores em jogo tanto para esses indivíduos inseridos em algum setor da sociedade marroquina quanto das visões recorrentes por parte deles e de suas redes de interação com a Europa ou, mais especificamente, com a França.

${ }^{16}$ Nas ciências sociais, o uso da biografia como recurso analítico foi tanto sugerida como metodo-
logia (BECKER, 1993) quanto, também, severamente criticada como "ilusão" (BOURDIEU, 1996). 


\section{'Ali, um religioso sufi'}

A visita à vila de Sidi 'Ali, ${ }^{18}$ reduto da ordem sufi [tariqa; pl. turuq] Hamdouchia, ${ }^{19}$ proporcionou o meu reencontro com 'Ali, 45 anos, casado, produtor de azeitonas e descendente do santo local. Membro importante da política entre as aldeias de Zebel Zerhoun (região montanhosa de Meknes) e dono do hotel Marhaban ${ }^{20}$ [seja bem-vindo], que serve de estadia para muitos peregrinos, suas impressões sobre os eventos ocorridos, envolvendo o jornal Charlie Hebdo, buscaram refletir sobre a situação à luz de um pensamento religioso dito "moderado", em comparação com os outros países. Ele definiu de "desastre político" a decisão de Mohammed VI não condenar publicamente, nos meios de comunicação, as charges e os atos de violência de Paris, em nome de um islã político engajado com a honra da comunidade ['umma] dos muçulmanos. "Em tempos de Hassan II [que reinou entre os anos de 1961 a 1999], a sacralidade do nosso profeta poderia ser feita de outras formas", disse ele. A moderação ${ }^{21}$ exigiria transparência nas posições tomadas tanto na desaprovação do uso da imagem do profeta Mohammed quanto nas estratégias de abordar essa questão entre seus súditos (no caso, a população marroquina).

'Ali tinha receio de que a figura suprema de comandante da crença [amir al-múminin], personificada no monarca, parecesse omissa quanto à gravidade do tema, porém, continuava a se manter distante de quaisquer críticas "graves" à pessoa deste. A proibição da reprodução das charges foi aprovada por ele, mas o fato de não haver uma posição "rígida", como nos tempos de seu pai (Hassan II), deixaria margem para que grupos interessados em crescer politicamente pu-

\footnotetext{
${ }^{17} \mathrm{O}$ sufismo, dentro da tradição religiosa do islã, pode ser definido como a busca de uma experiência direta com Deus (BALDICK, 1989; EVANS-PRITCHARD, 1949; SCHIMMEL, 1975; TRIMINGHAM, 1971). Essa meta é considerada a expressão de um processo longo de iniciação realizado por um indivíduo através de um caminho ou via mística [tariqa], sob a orientação de um mestre [shaykh].

${ }^{18}$ A vila rural de Sidi 'Ali (distrito de Mrhassiyine), localizada na província de Meknes-Tafilalet, possui uma história ligada ao nome de seu santo fundador (Sidi 'Ali ben Hamdouche) e está localizada a dezoito quilômetros da antiga capital imperial marroquina de Meknes.

${ }^{19} \mathrm{O}$ termo tariqa indica um método gradual envolvendo o que se denominou "misticismo contemplativo" entre os adeptos do sufismo, a partir da reunião de um círculo de discípulos sob a tutela de um mestre (shaykh). No contexto do sufismo marroquino, a Hamdouchia é uma comunidade religiosa que remonta sua centralidade a partir da figura do santo [wali; pl. awliya'], Sidi 'Ali ben Hamdouche (1666-1722), e que faz do controle da peregrinação [ziyara; pl. Ziyarat] ao túmulo [qbar, pl. Qbour] de seu fundador a sua raison d'être.

${ }^{20}$ Desenvolvi parte de minha pesquisa etnográfica de mestrado (BARTEL, 2013) nesse local por conta da facilidade de se entrar em contato com os visitantes, voltados aos mais variados circuitos de peregrinação na vila.

${ }^{21} \mathrm{O}$ valor da moderação é traduzido pela ideia de um diálogo constante, o que garantiria a chance de se evitar "os alardes apocalípticos que precedem os choques culturais, o ódio racial ou as ideologias nefastas". O termo ainda é muito valorizado no país e traduz a maioria dos ensinamentos políticos de Hassan II (LAURENT, 2000, p. 8).
} 
dessem surgir e se afirmar. Associações ligadas à salafiyya no Marrocos, por exemplo, eram o maior motivo de preocupação por parte de 'Ali, uma vez que a condenação das charges do jornal Charlie Hebdo seria algo a ser feito sempre, ainda que trouxesse à tona a questão das apropriações indevidas estampadas nos conteúdos da MarocHebdo.

É claro que sou contra o uso das imagens do nosso profeta. Mas também sou contra a violência em Paris aos cartunistas. Por isso, Mohammed VI deveria intervir junto aos políticos da Europa. O nosso Rei não nos serve? A publicação que saiu daqui [MarocHebdo] também não ajudou para uma solução do problema. Como explicar para a Europa que eles não podem fazer o que querem? Eu penso que o destaque que [os europeus] deram [a] Mohammed Fizazi prejudica o islã praticado no Marrocos. Ninguém quer saber mais de sufismo. A moderação está longe de reinar hoje em dia.

A liberdade de imprensa no Marrocos se associa aos interesses políticos dos grupos sociais para a manutenção ou extensão de sua autoridade, ou seja, a de promover uma legitimidade sobre o conteúdo referido ao uso das imagens do profeta, como o que foi mobilizado pela publicação marroquina (MarocHebdo) filiada ao periódico satírico francês (Charlie Hebdo). 'Ali optou por seguir uma conduta que visa proteger os elementos sagrados, como é o caso da imagem do profeta, entretanto ele afirmou apontar as possíveis "inovações ao islã" (bid'a) que grupos políticos poderiam criar a partir dessas situações. Essas motivações, segundo ele, não apenas teriam um fundo religioso, como no caso do partido político recém-criado de Mohammed Fizazi. Resguardar a figura do profeta é um ato comum a todos os muçulmanos, porém, varia de acordo com os grupos. Os 'ulamas (estudiosos religiosos), sufis, salafistas e demais muçulmanos leigos elaboram valores compartilhados sobre a figura de Mohammed, porém apresentariam respostas de ações distintas: 1) para o "Ocidente”, a resposta baseada na "tradição" de repúdio pela representação do profeta já seria algo suficiente; 2 ) no Marrocos, essa resposta deveria contemplar as múltiplas facetas da sociedade marroquina: não apenas no sentido de unificar um valor já compartilhado, mas legitimando também uma autoridade sobre esses valores.

\section{Rachid, um proprietário "bon vivant"}

Dono de um restaurante italiano em um bairro de classe média alta na capital (Rabat), Rachid, 39 anos, solteiro, filho de um segundo casamento por parte de 
seu pai com uma italiana, procura se abster de qualquer discurso religioso extraído do livro sagrado dos muçulmanos (Alcorão) ou dos relatos da vida do profeta [hadith; pl. ahadith] para descrever o que aconteceu em Paris. Durante algumas de nossas conversas em seu estabelecimento, sempre regadas a vinho tinto e com cantores italianos ao fundo, ele acreditava na completa ignorância [jahilin] dessas pessoas que, em nome de uma suposta defesa da honra dos muçulmanos pelo mundo, se julgavam superiores para cometer assassinatos ou demais crimes. Rachid sempre apelava jocosamente, por exemplo, para a canção "Con Te Partirò” (com você partirei), de Andrea Bocelli, para justificar que a busca por uma bela mulher na Europa (de olhos verdes, segundo sua preferência) seria bem melhor do que restringir a vida de alguém ao policiamento ideológico da imagem do islã na Europa ou saber punir um cartunista difamador das crenças religiosas segundo as leis islâmicas [shari'a].

Entretanto, mesmo que Rachid não se considere um muçulmano devoto [ $s a-$ lih], ele recorria a expressões comuns presentes entre quaisquer muçulmanos e também oscilava nas suas posições quanto ao comportamento dos europeus diante de alguns valores relevantes para o islã. Boa parte de sua socialização na Itália não significou uma conversão por completo aos valores do "Ocidente", mesmo que o modelo do secularismo europeu apareça para ele como um projeto a ser almejado cada vez mais no Marrocos contemporâneo; não somente para ele, mas, segundo o próprio, para toda uma população que ainda se encontra cerceada pela religião. Para ele, a capa do Charlie Hedbo com o profeta acompanhado dos dizeres "Tout est Pardonne" (está tudo perdoado) poderia ser liberada no país (o que reforça a sua crença no ideal de uma vida secular), mas também não poupou comentários contrários quanto aos conteúdos recorrentes das edições passadas.

Eu sou árabe, marroquino, europeu [em referência à sua condição ítalo-marroquina] e muçulmano, mas isso que aconteceu não tem nada a ver com a minha religião. O profeta Mohammed [S.A.A.S] ${ }^{22}$ não aceitaria tal coisa em seu nome em nenhum lugar do mundo. Mas uma coisa trágica mexeu com a Europa agora. Eu não sou contra as charges nem contra os jornais que procuram valorizar a campanha de liberdade da imprensa na França [leia-se secularização]. Mas será que agora eles [os europeus não muçulmanos] vão apreender e parar de fazer as charges sobre ele?

\footnotetext{
${ }^{22}$ Essa é a abreviação da expressão sallallahu 'alayhi wa sallam que significa "que a benção e a paz de Deus estejam sobre ele".
} 
Apesar de considerar que a capa da MarocHebdo não teria qualquer impacto na Europa (a não ser a difusão do estereótipo de um fundamentalismo por parte dos muçulmanos: "Para que se dão voltas na Kaaba ${ }^{23}$ fora do período de sua peregrinação? Eles estão planejando algo por lá?”, questiona ele), a sua preocupação mais geral era quanto ao desfecho do sentimento anti-islã deixado pelos atentados e pela omissão de Mohammed VI em participar da caminhada, junto com os demais líderes europeus e mundiais, em defesa da liberdade de imprensa e de expressão francesa. Os deslocamentos de Rachid para a Europa não seriam afetados devido à sua dupla nacionalidade (italiana e marroquina), entretanto, isso não o impediu de expor suas opiniões sobre as possibilidades de se usar a imagem do profeta Mohammed (ora tido como sagrado, ora como profano, para ele) ou de continuar a perpetuar um estereótipo de um islã "tradicional" e "ortodoxo", em termos de um orientalismo (Said, 1990), ou seja, de uma representação que o Ocidente faz do Oriente como seu próprio avesso, dentro e/ ou fora do Marrocos. O desejo de uma prudência (a ideia de moderação, como em 'Ali), por parte dos dois lados, seria um elemento que permitiria a manutenção do estilo de vida desse interlocutor, mesmo que muitas vezes os seus interesses possam ser conflitantes entre um "modo como as coisas deveriam ser" e um "modo como as coisas estão sendo postas" atualmente.

\section{Considerações finais}

As disputas em jogo, tanto na mídia quanto entre meus interlocutores, abrem uma margem de manobra baseada em interesses de controle, silenciamento ou até mesmo apagamento (Barth, 2005; Elias; SCOTSON, 2000; ${ }^{24}$ To-

\footnotetext{
${ }^{23}$ Construção cúbica da cidade de Meca reverenciada pelos muçulmanos e que marca a quebra dos ídolos cultuados entre as tribos da Península Arábica, tanto pelo profeta Abraão quanto por Mohammed, no ano de $630 \mathrm{~d}$. C.

${ }^{24}$ Em outra direção, o par estabelecidos-outsiders iluminou as relações de poder, a partir do princípio de antiguidade entre os moradores de um bairro popular na Inglaterra que procuravam encarnar os valores da "tradição" e da "boa sociedade", como demonstrou o trabalho de Nobert Elias e John Scotson (2000). Seu foco abordou a maneira como um grupo de pessoas foi capaz de monopolizar as oportunidades de poder e utilizá-las para marginalizar e estigmatizar membros de outro grupo muito semelhante (por exemplo, por meio do instrumento da fofoca) e as maneiras como isso era vivenciado nas "imagens" de um "nós", de ambos os grupos, em suas autoimagens coletivas. Entretanto, o que não desapareceu foi a imagem que os bairros mais antigos tinham do mais recente, com seu índice de delinquência antes mais elevado. Os bairros mais antigos continuavam a estigmatizá-lo como uma área em que a delinquência, supostamente, se proliferava. O eixo central dessas situações foi a percepção de um equilíbrio instável de poder a partir das tensões que lhe eram inerentes na constituição dos processos de autoafirmação de uma posição ou imagem de si perante um "outro".
} 
dorov, 1995 ${ }^{25}$ dessas experiências diante de um "outro". A figura do profeta estabelece noções hierarquizadas segundo os valores do islã. Não seria demais repetir que esses atributos não se encontrariam dispostos simplesmente sob a forma de grupos isolados uns dos outros, mas sim que esses mesmos grupos manteriam entre si relações definidas de tal modo que seu conjunto formaria um só e mesmo, um todo (Durkheim; Mauss, 2005). As definições sobre o que viria a ser "um islã”, de ser "muçulmano" ou de se ter "liberdade de expressão" foram os centros das disputas desses grupos que, a partir de seus valores (especialmente os do campo religioso), se posicionaram na sociedade marroquina.

Em primeiro lugar, a proibição imposta ao Charlie Hebdo e a contestação do uso da imagem do profeta Mohammed, por meio da revista MarocHebdo, identifica o Marrocos como pertencente à comunidade islâmica ['umma] através de um processo de transnacionalização dessa "comunidade imaginada" (Anderson, 2008), onde se tem a percepção compartilhada de que os "muçulmanos" e o "islã" estão sob ataques e necessitam de defesa (Eickelman; Piscatori, 1996). A (re)invenção dos muçulmanos na Europa após os ataques de 11/09, através do rótulo de "terroristas", faz com que seus praticantes criem novas fronteiras de diferenciação entre eles, algo inscrito na produção de alteridades tanto entre si quanto em relação aos "novos outros". As linhas desses pertencimentos refletem os interesses dos grupos, mas também os posicionamentos dos indivíduos, consciente ou inconscientemente, com relação ao senso comum e às associações de determinadas alianças políticas.

Em segundo lugar, a questão dos marroquinos que vivem na França estabelece uma maior tensão para as "minorias muçulmanas" numa Europa cada vez menos tolerante à presença do que se convém denominar "islã" e suas formas de atuação (ora de invisibilidade, ora de promoção no espaço público) no velho continente (MAPRIL, 2012). As negociações dessas fronteiras de distinção passam também por uma reelaboração dos processos de objetificação, como é o caso das charges envolvendo o profeta. A liberdade de expressão como valor exaltado no "Ocidente" foi incorporada por grande parte da comunidade marroquina em solo francês, mas, também, encontrou vozes consoantes existentes no Marrocos não somente na manifestação

${ }^{25}$ Para exemplificar de forma drástica o que procuro dizer, sobre as formas de alteridade realizadas nos campos de concentração pela Alemanha nazista, Tzvetan Todorov (1995) indicou os argumentos recorrentes, ou seja, o "senso comum" de guardas e demais funcionários dessa "máquina de extermínio” para se referir aos graus de percepção desses experimentos. As afirmações de que "tudo aquilo jamais existiu", "eu não sabia”, "eu obedecia a ordens" e de que "os outros fazem a mesma coisa” (Todorov, 1995, p. 152) resumiram o princípio de identificação e de classificação sobre quem seria considerado como parte de uma humanidade ou quem seria excluído dela. O interessante dessa reflexão (mesmo no caso das experiências produzidas pelo nazismo) é pensar que algumas formas provenientes desse "senso comum" também se faziam ecoar entre as testemunhas desses eventos, bem como não era inusitado de ser reproduzido entre as suas vítimas. Seja como for, o que está em jogo é toda uma produção de valores que organizam grupos homogêneos como forma de enquadrar sempre um "outro" através de um ponto de vista; no caso, a partir da lente de um "nós". 
ocorrida na capital, que contou com o apoio das relações diplomáticas francesas dois dias depois dos ataques em Paris.

A significação moral contida nos discursos e nas práticas dos muçulmanos no Marrocos e, ao que parece, na França se move a partir de dispositivos advindos de várias fontes que formariam as suas "culturas" (Geertz, 1989). O senso comum e a objetificação a partir da figura do profeta Mohammed indicam ser um deles. Porém, as formas de se acionar esses valores atuam de maneiras particularizadas quando o assunto é apresentar os contornos que fazem dessas fronteiras sua raison d'être. Cada um procurou controlar sua imagem diante do que se diz ser o "outro". A distinção continua a ser um princípio dinâmico à espera de outras configurações a partir dos contextos particulares das relações desenvolvidas entre os dois países. Entretanto, as alteridades locais sempre tendem a produzir novas problemáticas relativas ao fenômeno da invenção de um "outro".

\section{Referências bibliográficas}

ANDERSON, Benedict. Comunidades imaginadas. São Paulo: Companhia das Letras, 2008. [1983].

ASAD, Talal. Formations of the Secular. Christianity, islam, modernity. Palo Alto: Stanford University Press, 2003.

BALDICK, Julian. Mystical Islam: an introduction to sufism. Londres: ib Tauris, 1989.

BARTEL, Bruno Ferraz. A ambiguidade do sagrado: o culto a Aisha Qandisha na vila de Sidi 'Ali, Marrocos. Dissertação (Mestrado em Antropologia). Instituto de Ciências Humanas e Filosofia. Universidade Federal Fluminense. Niterói, 2013.

BARTH, Fredrik. Os grupos étnicos e suas fronteiras. In: LASK, T. (Org.). O guru, o iniciador e outras variações. Rio de Janeiro: Contracapa Livraria, 2000. [1969].

Etnicidade e o conceito de cultura. AntroPolitica, v. 19, n. 2, p. 15-30, 2005. [1995].

BECKER, Howard. A história de vida e o mosaico científico. In: (Org.). Métodos de pesquisa em ciências sociais. São Paulo: Hucitec, 1993.

BOURDIEU, Pierre. A ilusão biográfica. In: AMADO, J.; FERREIRA, M. de M. (Orgs.). Usos e abusos da história oral. Rio de Janeiro: Editora da FGV, 1996. [1986].

DURKHEIM, Émile. As formas elementares de vida religiosa. São Paulo: Paulus, 2008. [1912].

DURKHEIM, Émile; MAUSS, Marcel. Algumas formas primitivas de classificação: contribuição para o estudo das representações coletivas. In: Ensaios de sociologia. São Paulo: Perspectiva, 2005. [1903].

ELIAS, Norbert; SCOTSON, John L. Introdução: ensaio teórico sobre as relações estabelecidos-outsiders. In: Os estabelecidos e os outsiders: sociologia das relações de poder a partir de uma pequena comunidade. Rio de Janeiro: Jorge Zahar, 2000. [1965]. 
EICKELMAN, Dale; PISCATORI, James. Muslim Politics. Princeton: Princeton University Press, 1996.

EVANS-PRITCHARD, Edward Evan. The Sanusi of Cyrenaica. Oxford: Clarendon Press, 1949.

FAVRET-SAADA, Jeanne. Comment Produire une Crise mondiale avec douze petits dessins. Paris: Éditions Les prairies ordinaires, 2007.

GEERTZ, Clifford. O senso comum como sistema cultural. In: (Org.). O saber local. Novos ensaios em antropologia interpretativa. Petrópolis, Vozes, 2006. [1983].

. A interpretação das culturas. Rio de Janeiro: LTC, 1989. [1973].

LAURENT, Eric. Le Génie de la moderation. Réflexions sur les verites de l'islam par Hassan II. Paris: Plon, 2000.

LÉVI-STRAUSS, Claude. Raça e História. In: Antropologia Estrutural Dois. São Paulo: Cosac Naify, 2013. [1952].

MAPRIL, José. Islão e transnacionalismo. Uma etnografia entre Portugal e o Bangladeche. Lisboa: Imprensa de Ciências Sociais, 2012.

PINTO, Paulo Gabriel Hilu da Rocha. Islã: religião e civilização: uma abordagem antropológica. São Paulo: Ed. Santuário, 2010.

SAID, Edward W. Orientalismo: o Oriente como invenção do Ocidente. São Paulo: Companhia das Letras, 1990. [1978].

SCHIMMEL, Annemarie. Mystical Dimensions of Islam. Chapel Hill: University of North Carolina Press, 1975.

TODOROV, Tzvetan. Em face do extremo. Campinas (SP): Papirus, 1995. [1991]. TRIMINGHAM, J. Spencer. The Sufi Orders in Islam. Oxford: Oxford University Press, 1971.

WAGNER, Roy. A invenção do eu. In: (Org.). A invenção da cultura. São Paulo: Cosac Naify, 2010. [1975].

autor

\section{Bruno Ferraz Bartel}

Doutorando em Antropologia pelo Programa de Pós-Graduação em Antropologia pela Universidade Federal Fluminense (PPGA/ UFF). Integrante do Instituto de Estudos Comparados em Administração Institucional de Conflitos (INCT-InEAC) e do Núcleo de Estudos do Oriente Médio (NEOM). Realizou pesquisas etnográficas na comunidade muçulmana sunita do Rio de Janeiro (SBMRJ) e na vila rural de Sidi 'Ali (região Fez-Meknes), Marrocos. Atualmente realiza uma pesquisa etnográfica na região Fez-Meknes e nas cidades de Rabat e Safi. Atua nos seguintes temas: antropologia da religião, ritual e simbolismo e antropologia política. 